\title{
Lindsay tumor: An unusual entity: A case study with review of literature
}

\begin{abstract}
Solid, encapsulated, follicular variant of papillary carcinoma of thyroid is termed as Lindsay tumor. Follicular carcinoma carries a worse prognosis than papillary thyroid carcinoma with higher incidence of hematogenous metastasis. Lindsay tumor being encapsulated follows an indolent course and has a better outcome. We present a rare case of Lindsay tumor in a 30 years adult male who presented with hoarseness of voice.
\end{abstract}

Key words: Encapsulated; follicular; Lindsay; papillary; thyroid

\section{Introduction}

Previously, thyroid tumors exhibiting more than $50 \%$ follicular growth pattern were classified as follicular carcinoma. Recently, the follicular tumors regardless of percentage of follicular pattern are classified on the basis of the presence or absence of nuclear features of papillary thyroid carcinoma (PTC-N) viz., nuclear inclusions, nuclear grooves, ground glass appearance, elongated overlapping nuclei, and nuclear irregularity. Hence, the follicular tumors with nuclear features of papillary carcinoma are categorized as follicular variant of PTC (FVPTC). ${ }^{[1]}$ They exhibit biologic and molecular properties that distinguish it from conventional PTC. Controversies still exist with respect to the histologic diagnosis and categorization of FVPTC. Lindsay ${ }^{[2]}$ first coined the term FVPTC for a follicular pattern dominant PTC, and later Chen and Rosai ${ }^{[3]}$ reported the detailed morphologic description of this tumor. The diagnosis of encapsulated, follicular variant of papillary carcinoma (EnFVPC) relies on the solid nature, its encapsulation and characteristic nuclear features of PTC-N. Rosai stated that for the diagnosis of EnFVPTC, PTC-N needs to be displayed predominantly throughout the neoplasm. ${ }^{[4]}$ Although typically arising within the thyroid gland, occurrence in other organ sites, including the ovaries in struma ovarii ${ }^{[5]}$ and lingual thyroid ${ }^{[6]}$ has been reported.

\begin{tabular}{|l|c|}
\hline \multicolumn{2}{|c|}{ Access this article online } \\
\hline \multirow{2}{*}{ Website: } & Quick Response Code \\
\cline { 2 - 2 } www.asjo.in & DOI: \\
10.4103/2454-6798.180582 & \\
&
\end{tabular}

\section{Case Report}

A 30-year-old male came with chief complaints of hoarseness of voice due to thyroid enlargement since 6 months. On examination, thyroid appeared nodular. No lymphadenopathy was noted. Thyroid function tests were within normal limits. Ultrasound examination showed a hyperechoic solid mass suggesting a neoplasm. A subtotal thyroidectomy was performed. Gross examination showed nodular thyroid measuring $5 \mathrm{~cm} \times 4 \mathrm{~cm} \times 3.5 \mathrm{~cm}$. Cut section showed an encapsulated tumor measuring $3 \mathrm{~cm}$ in diameter with focal gray-white and brownish areas [Figure 1]. Histological examination showed an encapsulated tumor composed of microfollicular [Figure 2] and papillary pattern with numerous psammoma bodies [Figure 3]. The follicles were seen lined by cuboidal cells with eosinophilic cytoplasm and small, round nuclei. Nuclei at places showed an optically clear nucleoplasm with nuclear grooves [Figure 4]. Meticulous search for

\section{Yasmin Altaf Momin, Sameer A. H. Ansari, BhARAT A. GHODKe \\ Department of Pathology, Grant Government Medical College and Sir J. J. Hospital Groups, Mumbai, Maharashtra, India}

Address for correspondence: Dr. Sameer A. H. Ansari, Grant Government Medical College and Sir J. J. Hospital Groups, Mumbai, Maharashtra, India.

E-mail: drsameeransari@yahoo.co.in

This is an open access article distributed under the terms of the Creative Commons Attribution-NonCommercial-ShareAlike 3.0 License, which allows others to remix, tweak, and build upon the work non-commercially, as long as the author is credited and the new creations are licensed under the identical terms.

For reprints contact: reprints@medknow.com

How to cite this article: Momin YA, Ansari SA, Ghodke BA. Lindsay tumor: An unusual entity: A case study with review of literature. Asian J Oncol 2016;2:43-5. 


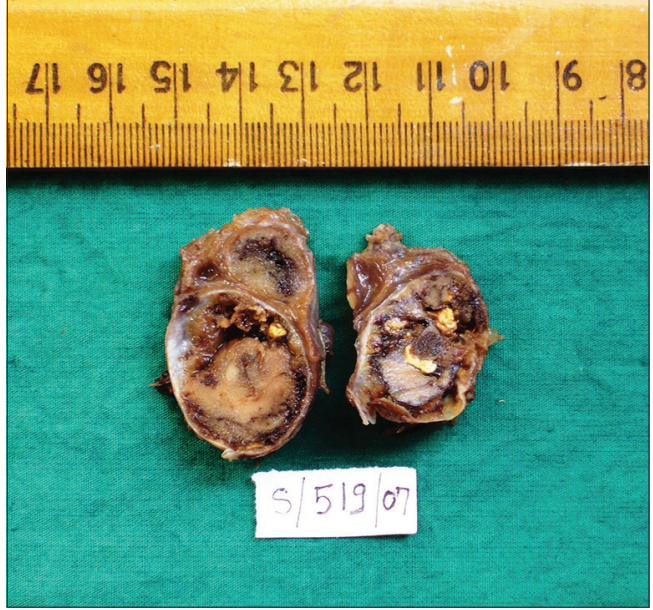

Figure 1: Gross photograph of thyroid showing an encapsulated tumor

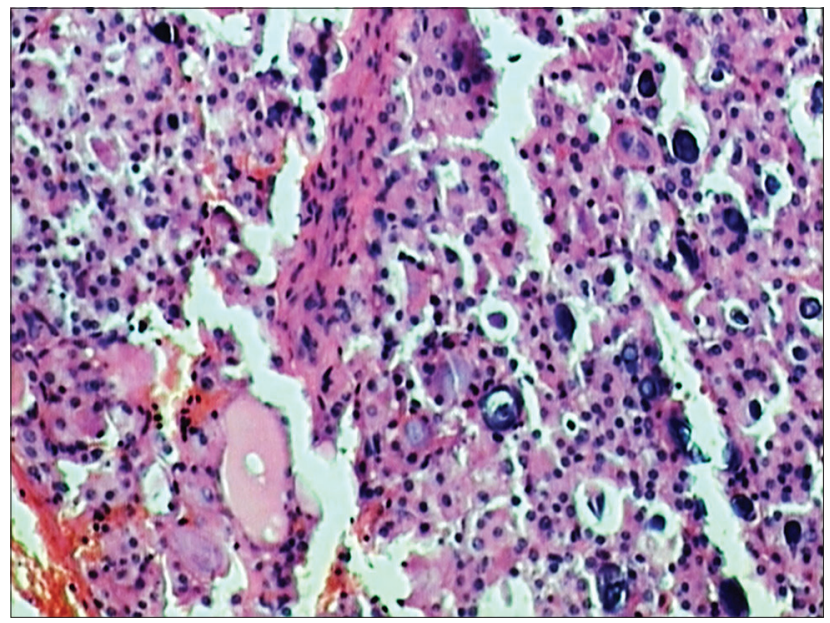

Figure 3: Microscopic examination showing numerous psammoma bodies ( $H$ and $E, \times 40$ )

capsular or vascular invasion revealed no evident invasion. We rendered a diagnosis of solid, EnFVPTC-Lindsay tumor.

\section{Discussion}

Thyroid lesions with encapsulated follicular pattern include follicular adenoma, follicular carcinoma, and FVPTC. A study of the immunomarkers, galectin-3, cytokeratin 19 (CK19), Ret oncoprotein (RET), and HBME-1 have a high utility in differentiating benign lesions from malignant tumors. ${ }^{[7]}$ The finding of bland nuclear features and morphologically distinct features within and outside the capsule favor follicular adenoma. The diagnosis of follicular carcinoma requires the features of malignancy with the presence of capsular and/or vascular invasion. FVPTC is a follicular pattern dominant PTC with nuclear features of papillary carcinoma. ${ }^{[8-10]}$ The criteria which are mostly relied upon are in the decreasing order of frequency, nuclear clearing, very fine powdery chromatin, nuclear grooves, nuclear overlapping, nuclear membrane

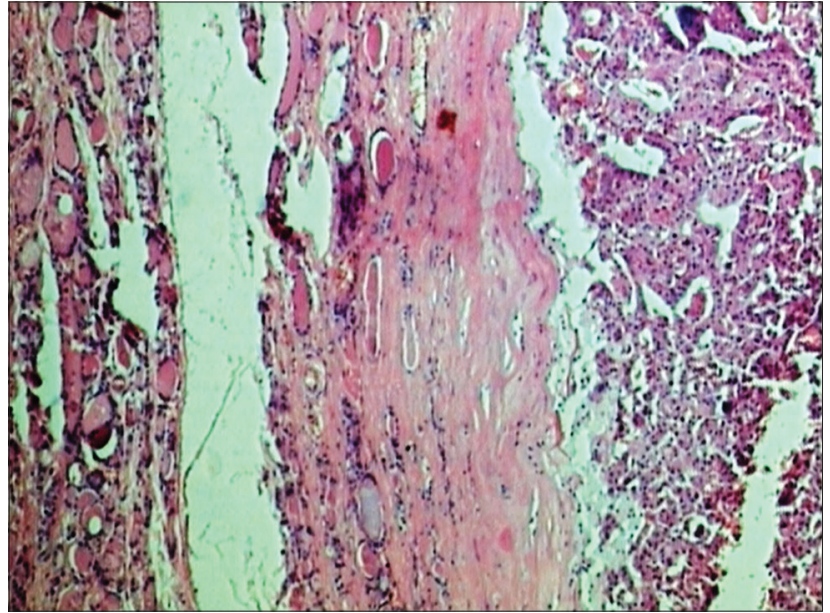

Figure 2: Scanner view to show thyroid with an encapsulated tumor with follicular pattern showing follicles of varying size $(H$ and $E, \times 10)$

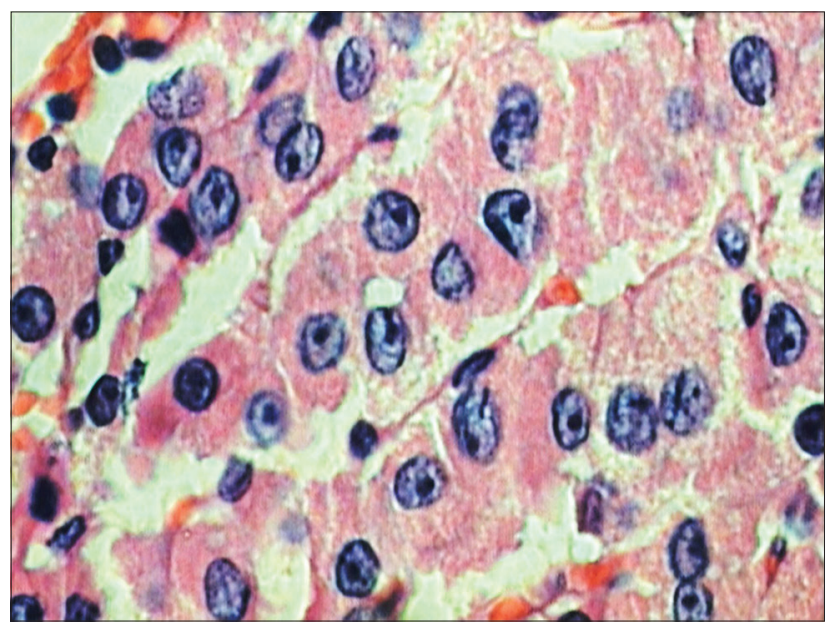

Figure 4: High-power view showing nuclear details of follicular cells with prominent nuclear grooves $(H$ and $E, \times 40)$

irregularity; and the secondary features such as chromatin margination, distorted follicular architecture, and fibrosis or sclerosis. ${ }^{[1-10]}$ As supported by many papers, it has been proved that FVPTC is characterized by a high prevalence of RAS mutations, a low prevalence of RET/PTC-1 rearrangement, and the absence of FTC-specific PAX8-PPAR $\gamma$ rearrangement. ${ }^{[8-10]}$ The diffuse variant and the encapsulated variant are two prognostically and morphologically distinct forms of FVPTC. Both the forms of FVPTC tend to have fewer calcifications and less psammoma body formation as compared to conventional PTC. However, numerous psammoma bodies were seen in our case. The diffuse variant of FVPTC demonstrates a higher rate of the BRAF V600E mutation, lymph node involvement, and distant metastasis thereby carrying a worse prognosis. The encapsulated variant of FVPTC, defined by a complete peritumoral capsule, has an excellent prognosis. ${ }^{[1-10]}$ Our case showed a unifocal, well-encapsulated tumor with no capsular or vascular invasion. Follicular carcinomas 
tend to be unicentric, angioinvasive, and metastasize hematogenously to bone and lung; such a pattern of spread is rare in conventional PTC which has a greater propensity for lymph node metastasis. FVPTC is multi-foci, with a higher rate of vascular invasion than conventional PTC. ${ }^{[1-10]}$ There are several varying conclusions regarding the treatment of EnFVPTC. Many authors, based on case reports, have pointed out that distant metastasis was found in a few cases of EnFVPTC, and they emphasized that EnFVPTC must be treated exhaustively. ${ }^{[1-9]}$ However, Chen et al..$^{[3,11]}$ have stated that a conservative approach for EnFVPTC is sufficient and can be managed like minimally invasive follicular carcinoma by lobectomy without radioactive iodine therapy. Our patient is well and free of metastasis after 2 years of follow-up.

\section{Conclusion}

EnFVPC-Lindsay tumor is a rare tumor of thyroid that carries low risk of metastasis and favorable prognosis and need to be differentiated from diffuse variant or nonencapsulated variant as the treatment modalities are different for these two distinct entities. ${ }^{[1]}$

\section{Financial support and sponsorship}

Nil.

\section{Conflicts of interest}

There are no conflicts of interest.

\section{References}

1. Baloch ZW, LiVolsi VA. Encapsulated follicular variant of papillary thyroid carcinoma with bone metastases. Mod Pathol 2000;13:861-5.

2. Lindsay S. Carcinoma of the Thyroid Gland: A Clinical and Pathologic Study of 293 Patients at the University of California Hospital. Springfield, IL: Charles C Thomas; 1960.

3. Chen KT, Rosai J. Follicular variant of thyroid papillary carcinoma: A clinicopathologic study of six cases. Am J Surg Pathol 1977;1:123-30.

4. Rosai J. The encapsulated follicular variant of papillary thyroid carcinoma: Back to the drawing board. Endocr Pathol 2010;21:7-11.

5. Celestino R, Magalhães J, Castro P, Triller M, Vinagre J, Soares P, et al. A follicular variant of papillary thyroid carcinoma in struma ovarii. Case report with unique molecular alterations. Histopathology 2009;55:482-7.

6. Hari CK, Kumar M, Abo-Khatwa MM, Adams-Williams J, Zeitoun H. Follicularvariant of papillary carcinoma arising from lingual thyroid. Ear Nose Throat J 2009;88:E7.

7. Saleh HA, Feng J, Tabassum F, Al-Zohaili O, Husain M, Giorgadze T. Differential expression of galectin-3, CK19, HBME1, and Ret oncoprotein in the diagnosis of thyroid neoplasms by fine needle aspiration biopsy. Cytojournal 2009;6:18.

8. Chen H, Izevbaye I, Chen F, Weinstein B. Recent advances in follicular variant of papillary thyroid carcinoma. N Am J Med Sci 2012;5:212-6.

9. Hedinger C, Williams ED, Sobin LH. Histological Typing of Thyroid Tumors. WHO International Histological Classification of Tumors. $4^{\text {th }}$ ed. Berlin: Springer-Verlag; 1988.

10. DeLellis RA, Lloyd RV, Heitz PU, Eng C. Tumours of the thyroid and parathyroid, Tumours of Endocrine Organs, World Health Organization Classification of Tumours; Pathology and Genetics. Chapter 2. Lyon: IARC Press; 2004; p. 49-134.

11. Gupta S, Ajise O, Dultz L, Wang B, Nonaka D, Ogilvie J, et al. Follicular variant of papillary thyroid cancer: Encapsulated, nonencapsulated, and diffuse: Distinct biologic and clinical entities. Arch Otolaryngol Head Neck Surg 2012;138:227-33. 